\title{
DEVELOPMENT OF AN INTEGRATED DIGITAL ELEVATION MODEL FOR SAFE TAKEOFF AND LANDING OF THE AIRCRAFT
}

\author{
Adam Ciećko, Wojciech Jarmołowski \\ Department of Satellite Geodesy and Navigation, \\ University of Warmia and Mazury in Olsztyn, Poland \\ e-mail: a.ciecko@kgsin.pl,wojciech.jarmolowski@uwm.edu.pl
}

\begin{abstract}
.
The article describes preliminary results of the augmentation of Global Navigation Satellite System/Inertial Navigation System positioning (GNSS/INS) by Digital Elevation Model (DEM) based on the data from the Shuttle Radar Topography Mission (SRTM) and data from field survey.

The prototype software is developed to refer the position of the aircraft to DEM and informs the user about the current relevant flight parameters. The number of the parameters may be arbitrarily increased, however, currently we investigate the altitude above the terrain and the aircraft position relative to the descent path and airfield.

The study provides some information on the local SRTM accuracy in relation to the field survey of the airfield "Dajtki" - Aeroclub of Warmia and Mazury in Olsztyn.
\end{abstract}

Keywords: GNSS, GNSS/INS, air navigation, STRM - Shuttle Radar Topography Mission, DEM - Digital Elevation Model.

\section{INTRODUCTION}

It is estimated that about one-third of serious accidents involving aircraft transport is the result of hitting the Earth's surface by a plane performing completely smooth and normal flight plan, run by well-prepared and efficient staff, these accidents are commonly called CFIT - Controlled Flight Into Terrain. One of the tragic example of CFIT accident is a crash of a Polish Air Force Tupolev Tu-154M aircraft in Smolensk (Russia), killing 96 people including President of Poland and his wife in April 2010. Since the beginning of commercial jet operations, more than 9,000 people have died worldwide because of CFIT. What's more, CFIT accidents lead amongst all other air transport accident types and result in the greatest number of fatalities. It is estimated that CFIT accidents comprise about $25 \%$ of the total accidents and cause about 32\% of the fatalities (ALAR Tool Kit, 2001). (ALAR stands for Approach and Landing Accident Reduction and it has been among the primary goals of the Flight Safety Foundation - FSF). It has also been estimated that about two-thirds of the accidents occur within eight miles of the runway with the majority of them occurring within three miles of the runway. Figure 1 presents vertical profiles of some recent CFIT accidents/incidents. In all of them there was a lack of vertical situation awareness. This leads 
to a conclusion that increased altitude awareness and better preflight planning would likely have prevented most of these accidents.

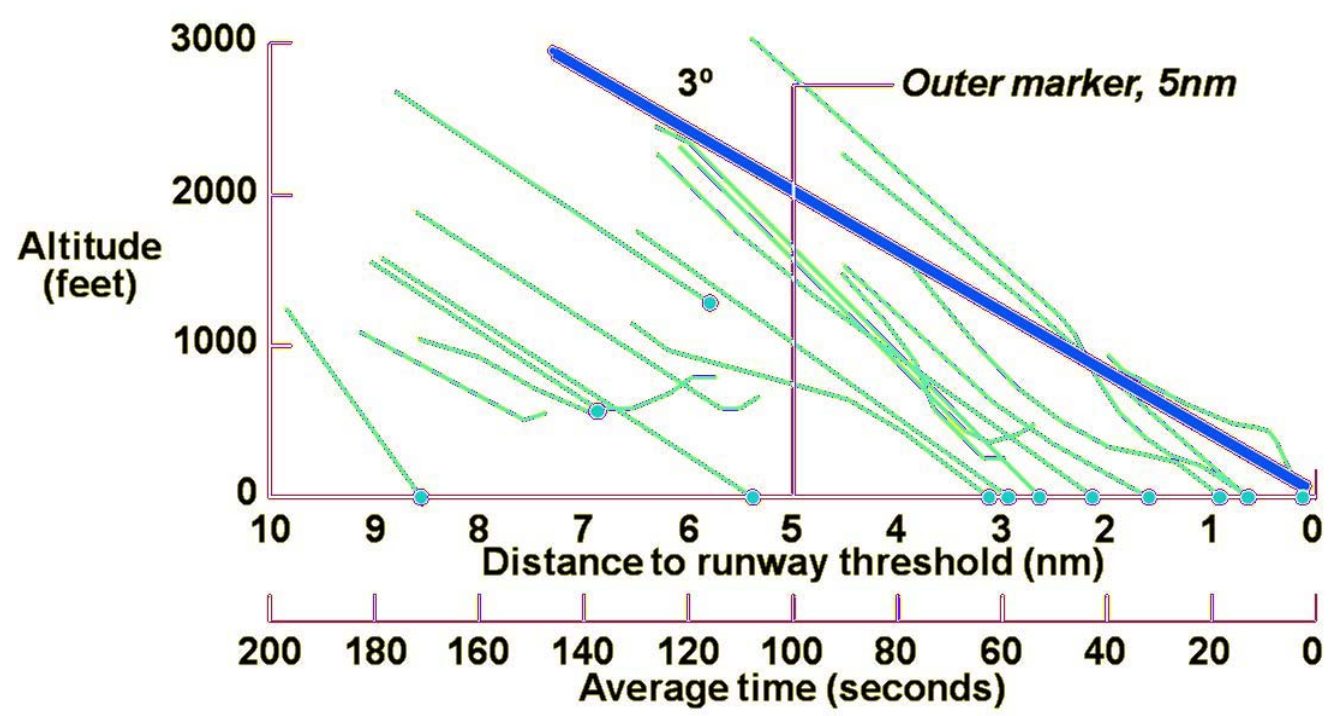

Fig. 1. Vertical profiles of some recent CFIT accidents/incidents (ALAR Tool Kit, 2001)

Presented statistics have induced authors of this paper to the idea of creation of the application which could help to prevent CFIT accidents in the future. Disasters are often caused by errors of pilots, but their incidence is always composed by many additional factors among which a central role play harsh weather conditions and unexpected equipment failures. Innovative application proposed in this article, which uses the best features of GNSS/INS positioning combined with digital elevation model of the airfield and surroundings as well as detailed information about air navigation obstacles in the vicinity of the aerodrome is certainly independent of weather and would increase the possibility of avoiding the tragedy in critical situations. The great advantage of the application is a possibility of adding to its database any kind of the airfield - even small grass airfields without any radionavigation aids. Worked out technology of data acquisition is fast, efficient, very accurate and cost-effective.

\section{TEST-BED}

For preliminary development and implementation of the application an airfield "Dajtki" in Olsztyn (ICAO code: EPOD) was selected. The airfield has two runways: concrete runway in the direction of $09 / 27$ with dimensions of $850 \mathrm{~m} \times 25 \mathrm{~m}$ and grass runway with dimensions of $850 \mathrm{~m} \times 100 \mathrm{~m}$. Very important aspect of the input data for the application is the location of the highest in Poland TV antenna mast with the height of 356 meters just 3,7 NM from the runway and in the close vicinity of the glide path. The distance from glide path to TV tower is less than $1 \mathrm{NM}-$ Fig. 2.

The elevation of $3^{\circ}$ glide path nearby the tower is almost the same as the top of the mast. Such location could be extremely dangerous in severe weather conditions with limited visibility. On the other hand this air navigation obstacle is also perfect for experiments and tests of algorithms and formulas used in the application. The official air navigation obstacles (AIP Poland) includes two more obstacles in Olsztyn - Table 1, which are much lower than TV tower and for the purposes of this article they were not taken into consideration. 


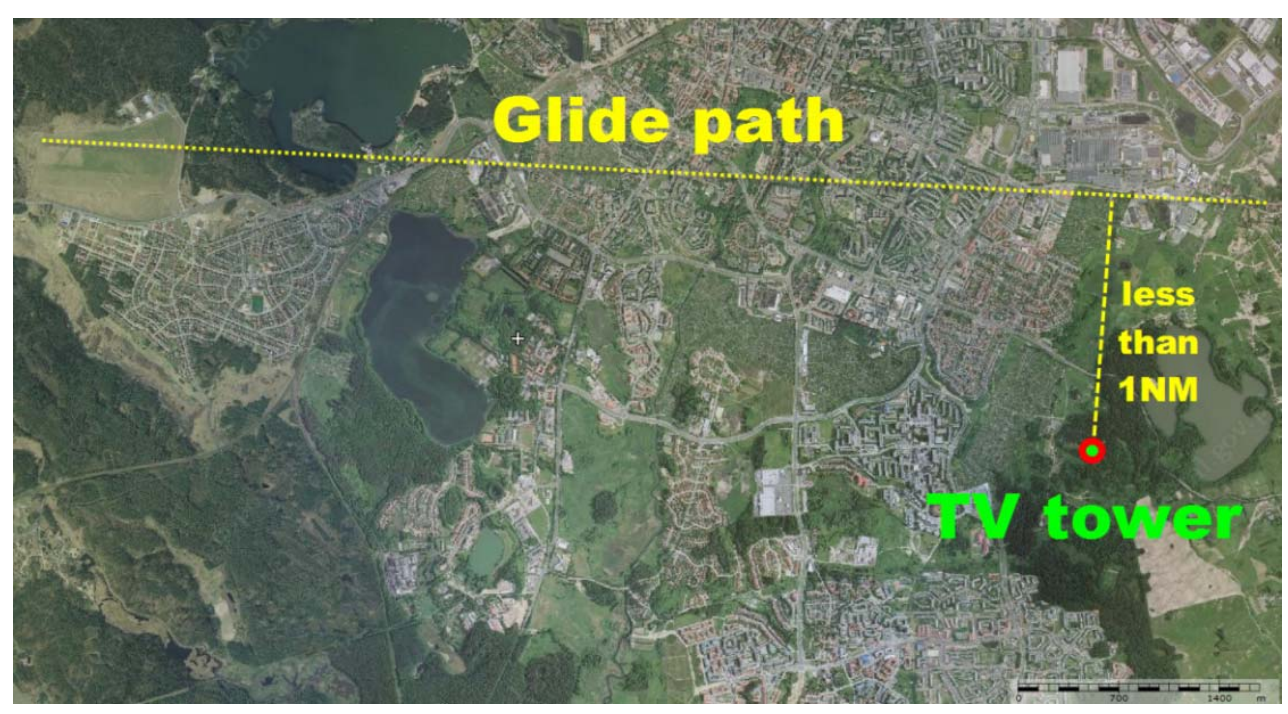

Fig. 2. Glide path of Olsztyn - Dajtki airport against the highest TV tower in Poland (www.geoportal.gov.pl)

Table 1. Air navigation obstacles (AIP Poland) in Olsztyn

\begin{tabular}{|c|c|c|c|c|c|c|c|c|}
\hline \multirow[t]{2}{*}{$\begin{array}{l}\text { Polożenie/ } \\
\text { Location }\end{array}$} & \multirow{2}{*}{$\begin{array}{c}\text { Numer } \\
\text { identyfikacyjny/ } \\
\text { Identification } \\
\text { number }\end{array}$} & \multirow{2}{*}{$\begin{array}{l}\text { Szerokość } \\
\text { geograficznal } \\
\text { Latitude }\end{array}$} & \multirow{2}{*}{$\begin{array}{l}\text { Długość } \\
\text { geograficzna/ } \\
\text { Longitude }\end{array}$} & \multirow[t]{2}{*}{$\begin{array}{l}\text { Rodzaj przeszkody/ } \\
\text { Type of obstacle }\end{array}$} & \multirow[t]{2}{*}{$\begin{array}{c}\text { Ilośćl } \\
\text { Quantity }\end{array}$} & \multicolumn{2}{|c|}{$\begin{array}{l}\text { Wysokośćl } \\
\text { Top of obstacle }\end{array}$} & \multirow{2}{*}{$\begin{array}{c}\text { Oświetle- } \\
\text { nie/ } \\
\text { Lighting }\end{array}$} \\
\hline & & & & & & $\begin{array}{l}\text { AGL } \\
(\mathrm{m})\end{array}$ & $\begin{array}{c}\text { AMSL } \\
(\mathrm{m})\end{array}$ & \\
\hline $\begin{array}{l}\text { Olsztyn/Stoneczny } \\
\text { Stok }\end{array}$ & & $53^{\circ} 44^{\prime} 48^{\prime \prime} \mathrm{N}$ & $020^{\circ} 26^{\prime} 31^{\prime \prime} \mathrm{E}$ & komin/chimney & 1 & 120 & 245 & tak/yes \\
\hline Olsztyn/Pieczewo & & $53^{\circ} 45^{\prime} 12^{\prime \prime} \mathrm{N}$ & $020^{\circ} 31^{\prime} 07^{\prime \prime} \mathrm{E}$ & maszt/mast & 1 & 356 & 506 & taklyes \\
\hline Olsztyn/Track & & $53^{\circ} 46^{\prime} 58^{\prime \prime} \mathrm{N}$ & $020^{\circ} 32^{\prime} 00^{\prime \prime} \mathrm{E}$ & wieżaltower & 1 & 105 & 241 & tak/yes \\
\hline
\end{tabular}

Airfield in Olsztyn is also surrounded by the forest which makes some limitations for the users and makes our application desirable. For the purposes of the project combination of two types of data is necessary as an input:

$>$ SRTM (Shuttle Radar Topography Mission) for the large areas surrounding the airfield,

$>$ field survey for the most accurate and precise DEM of the airfield.

\section{SRTM}

SRTM is an international project spearheaded by the National Geospatial-Intelligence Agency (NGA) and the National Aeronautics and Space Administration (NASA). The Shuttle Radar Topography Mission obtained elevation data on a near global scale (from $56^{\circ} \mathrm{S}$ to $\left.60^{\circ} \mathrm{N}\right)$ to generate the most complete high-resolution digital topographic database of the Earth (Rabus et al. 2003). SRTM consisted of a specially modified radar system that flew onboard the Space Shuttle Endeavour during an 11-day mission in February of 2000 - Fig. 3. The SRTM digital elevation data, produced by NASA is a major breakthrough in digital mapping of the world, and provides a major advance in the accessibility of high quality elevation data for large portions of the world. This 3 arc second $(90 \mathrm{~m})$ data is currently distributed free of charge by USGS and is available for download from the National Map Seamless Data Distribution System, or the USGS ftp site. The vertical error of the DEM's is frequently reported to be less than $16 \mathrm{~m}$, which is enough for global air navigation use and could be not sufficient for presentation of airfields and runways. The presence of a bias, which is usually larger than decimetres may definitely disqualify SRTM from precise approach investigations (Braun and Fotopoulos, 2007). 


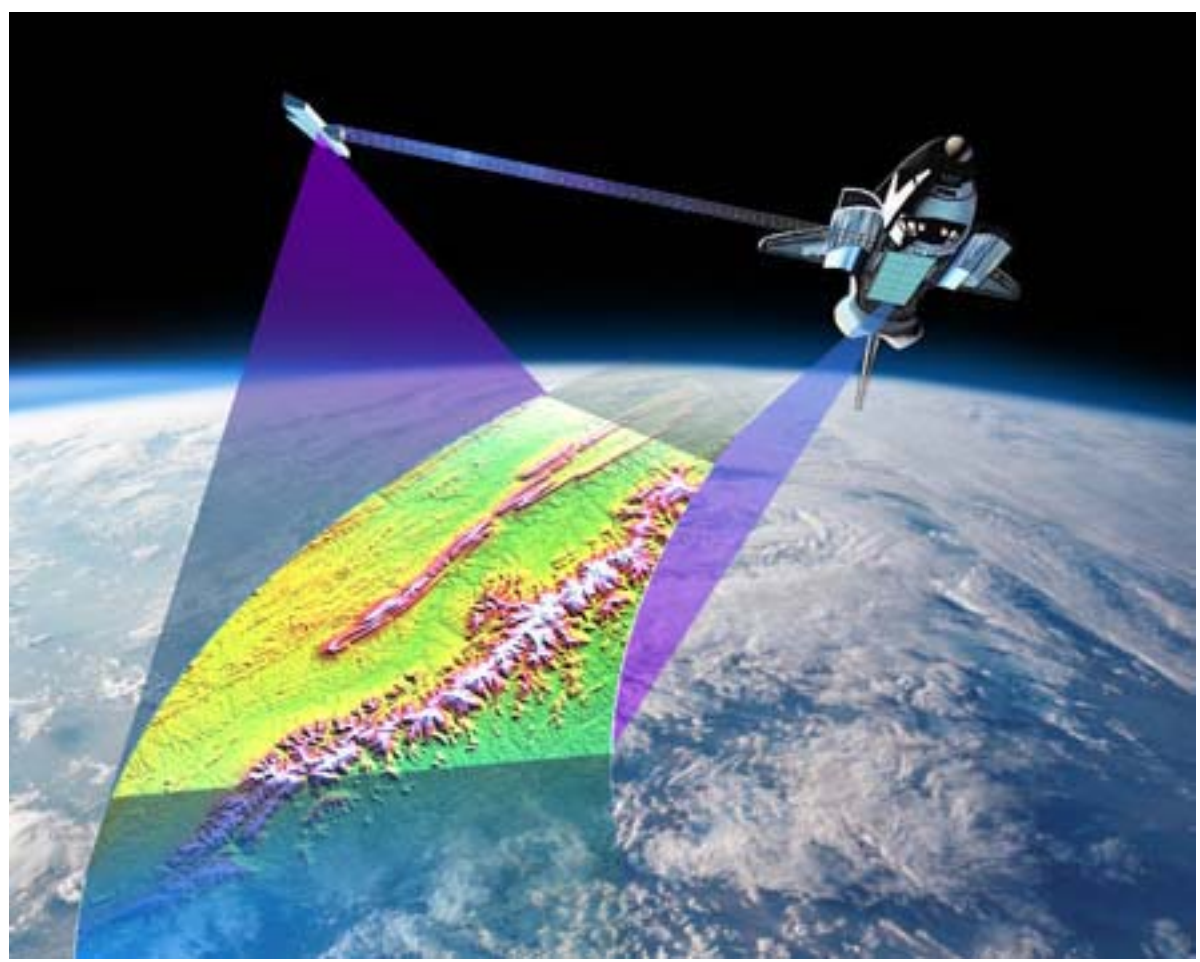

Fig. 3. Shuttle Radar Topography Mission (CGIAR-CSI)

The NASA Shuttle Radar Topographic Mission (SRTM) has provided digital elevation data (DEMs) for over $80 \%$ of the globe. The data currently being distributed by NASA/USGS (finished product) contains "no-data" holes where water or heavy shadow prevented the quantification of elevation. These are generally small holes, which nevertheless render the data less useful, especially in fields of hydrological modeling. Reuter, et al. (2007) have further processed the original DEMs to fill in these no-data voids. This involved the production of vector contours and points, and the re-interpolation of these derived contours back into a raster DEM. These interpolated DEM values are then used to fill in the original no-data holes within the SRTM data. This modified SRTM is available at CGIAR-CSI GeoPortal. SRTM data used for application presented in this paper uses model acquired from CGIAR-CSI GeoPortal (http://srtm.csi.cgiar.org). The fifteen CGIAR International Research Centers have pioneered the application of Geographic Information Systems (GIS) and Remote Sensing (RS) for sustainable agricultural development for more than a decade. In May 1999, they formed the Consortium for Spatial Information (CGIAR-CSI) which links the all of the CGIAR's GIS/RS laboratories, and the many geospatial scientists and researchers within the CGIAR system, with scientists and institutions from around the world. Together, these laboratories, scientists and researchers constitute a formidable assemblage of technical ingenuity, scientific expertise, and practical experience in spatial analysis.

It has been estimated that typical error of SRTM height in Poland in the warminsko-mazurki region is $3.7 \mathrm{~m}$ (Karwel and Ewiak, 2006). This value does not apply for the urbanized area, as well as for the forest. It must be stressed that the surface of SRTM may often represent top of the forest, and the height of the trees is changing in time. Our test area is surrounded by forest and real errors can significantly exceed above mentioned values (Sun et al. 2003). 


\section{INTEGRATION OF SRTM MODEL WITH PRECISE DEM}

In order to obtain accurate and precise DEM of the airfield and runways field survey was made with the use of modern and innovative technology - Leica Viva TS15 Total Station and All-Terrain-Vehicle (ATV) for fast and cost-effective data collection (Ciecko et al., 2006a, 2006b). The Leica Viva TS15 is a robotic Imaging Total Station which provides advanced imaging functionality combined with dynamic tracking capabilities for one-person surveying (Fig. 4).

Before the proper measurement a network of 4 geodetic points was established along the concrete runway of the airfield. The coordinates of these points were determined with centimeter accuracy on March 26, 2012 with the use of GNSS static measurement (2 hours session). For effective data collection the measurement profiles were designed in MicroMap Software. Prepared profiles were uploaded to Thales MobileMapper Pro GPS receiver which was used for real time navigation during filed measurements (Popielarczyk, 2011). Field survey of the airfield was made on March 30, 2012. Leica Viva TS15 was placed on the network point with the highest elevation to allow best visibility of the $360^{\circ}$ prism which was placed on specially built frame attached to the ATV. Beside Leica prism, there were several GNSS receivers placed on a frame in order to examine accuracy of different methods of GNSS kinematic positioning. On the top of the prism antenna of Septentrio AsteRx2i HDC a dual-frequency GPS/ GLONASS/INS receiver was placed. Next to the prism, Thales MobileMapper Pro was used for real-time navigation along the profiles. On both edges of the frame two GNSS Trimble SPS 882 receivers, working in post-processing mode were used. The ATV equipped with measurement devices is presented in Fig. 4.
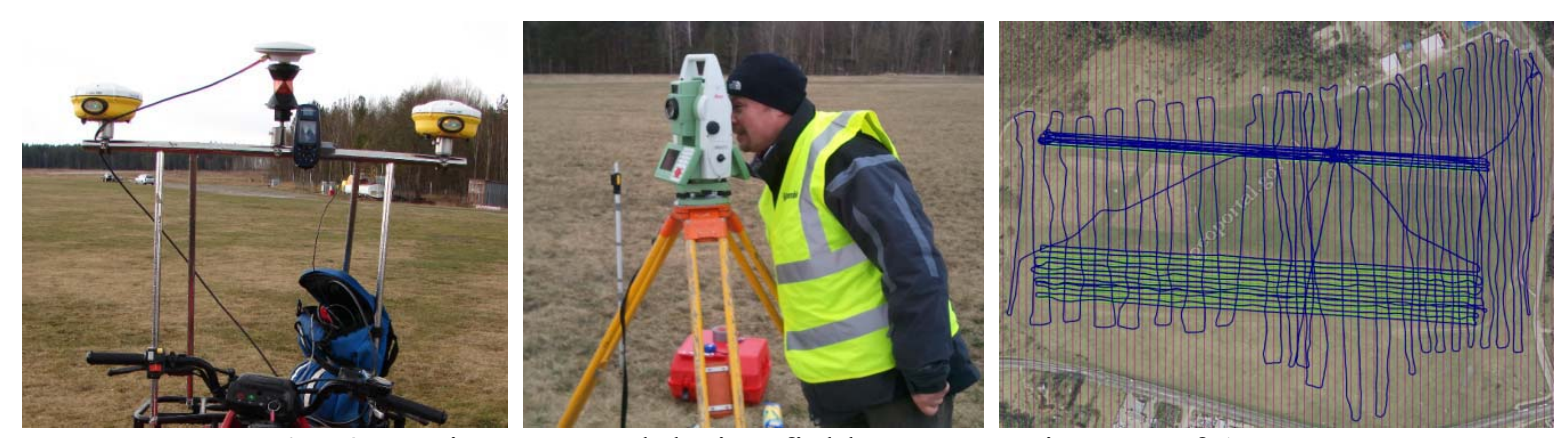

Fig. 4. Equipment used during field survey; trajectory of ATV

against designed profiles

Practical measurements due to a powerful and reliable Honda Recon ATV were done quickly and effectively. The area of about 60 hectares was measured during one day in just 5-6 hours. Leica TS15 assures the acquired data reliable and with centimeter accuracy. The automatic prism tracking was lost for several times by Leica TS15, nevertheless this instrument appears as perfect and irreplaceable for quick and accurate data acquisition for DEM creation. Recorded trajectory along measurement profiles against airfield is given in Fig. 4.

After collection of field data a process of integration with SRTM model was necessary. For the purposes of this project a part of SRTM downloaded from CGIAR-CSI GeoPortal was used. The size of applied SRTM was about 10x10 kilometres and it covered the area of Olsztyn city and surroundings. Applied part of SRTM used for this study, with trajectory of the test flight is presented in Fig. 5. The original SRTM expresses elevation above sea level, for convenience of further analyses and calculations it was as reduced to the ellipsoidal height using constant height anomaly $\zeta$ equal $29.8 \mathrm{~m}$. The slope of the quasigeoid is in the range of a few centimeters at the area of Olsztyn city, therefore due to the considerations at the 
decimeter level, it can be neglected. The value of the height anomaly is computed from the EGM96 geopotential model and compared to the local quasigeoid which was coherent with the global model derived from the website. Although the approximate geoid was useful for the preliminary test, one should remember that the coherency observed was only accidental and care should be taken with the choice of vertical reference level because of limited accuracy of the global models and significant biases between them (Trojanowicz 2009, Erol 2012). The ellipsoidal height reads:

$$
\mathrm{h}_{\mathrm{P}}=\mathrm{H}_{\mathrm{P}}^{\mathrm{n}}+\zeta_{\mathrm{P}}
$$

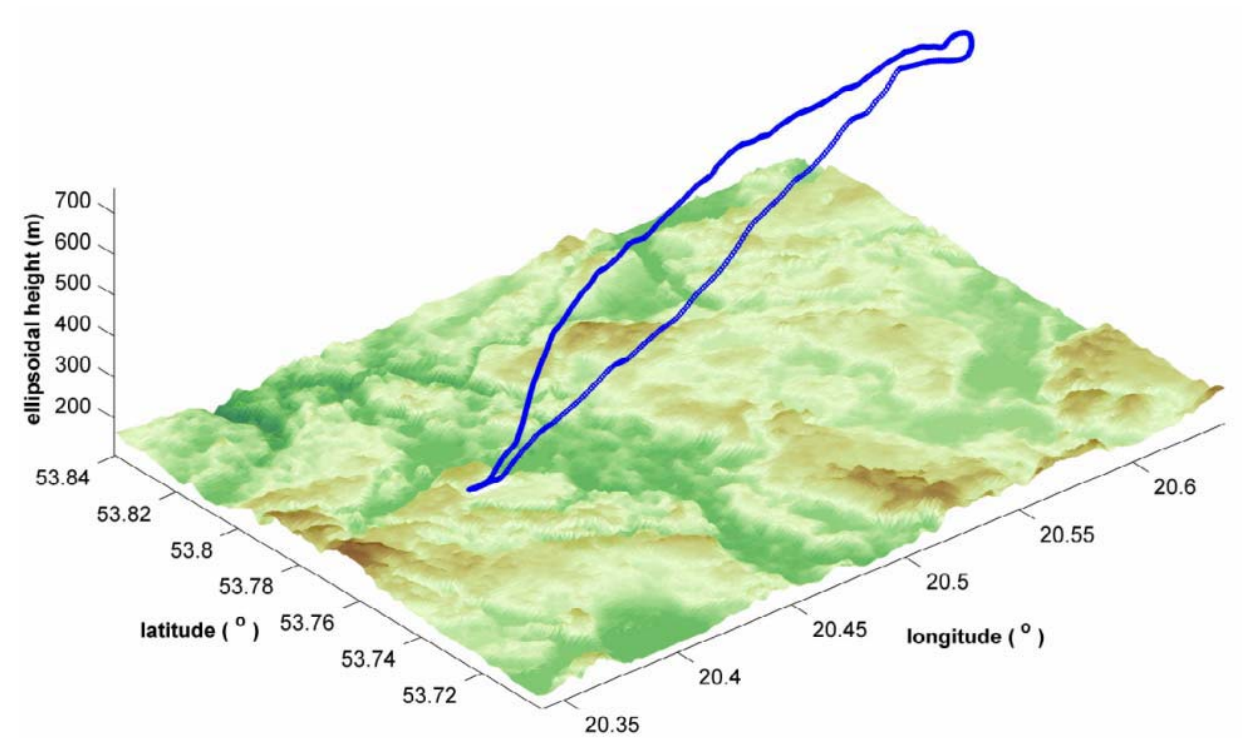

Fig. 5. SRTM model of Olsztyn city and trajectory of test flight (blue).

The precise DEM of the airfiled was created using data collected from field survey and compared with SRTM data. It must be stressed that the resolution of SRTM is about 90 meters ( 3 seconds) and the precision of elevation data is one metre. While the resolution of precise DEM is 30 meters with centimeter precission and centmeter accuracy of elevation data. Two DEM models of the airfield were developed by Least Squares Collocation (Hofmann-Wellenhof and Moritz, 2005). The same software was used for comparisons and analysis. In the Figure 6a and 6b two DEM models of the airfield are presented, one with resolution of 3" (SRTM) and second with resolution 1" (precise DEM). The general shape of the model of the airfiled is preserved by the SRTM model, however there are visible differences especially on the edges of both models. These differences are probably caused by the forest which surrounds the airfield. Detailed comparison of both models revealed differences in the range of -3 to +5 meters (Fig. 6c). The highest differences are observed in eastern part of the airfield where the beginning of runway for landing plane is located. The difference of 5 meters is significant and should be taken into consideration for any type of a navigation aid. Moreover, for limited area the slope of the differences (Fig. 6c) may indicate that some systematic effects exist also in total SRTM error. Systematic error is clearly visible on histogram (Fig.7) representing error of SRTM model with respect to precise DEM. These errors may come from e.g. modelling of heterogeneous data composed of terrain and top of the forest. 
a) SRTM 3"

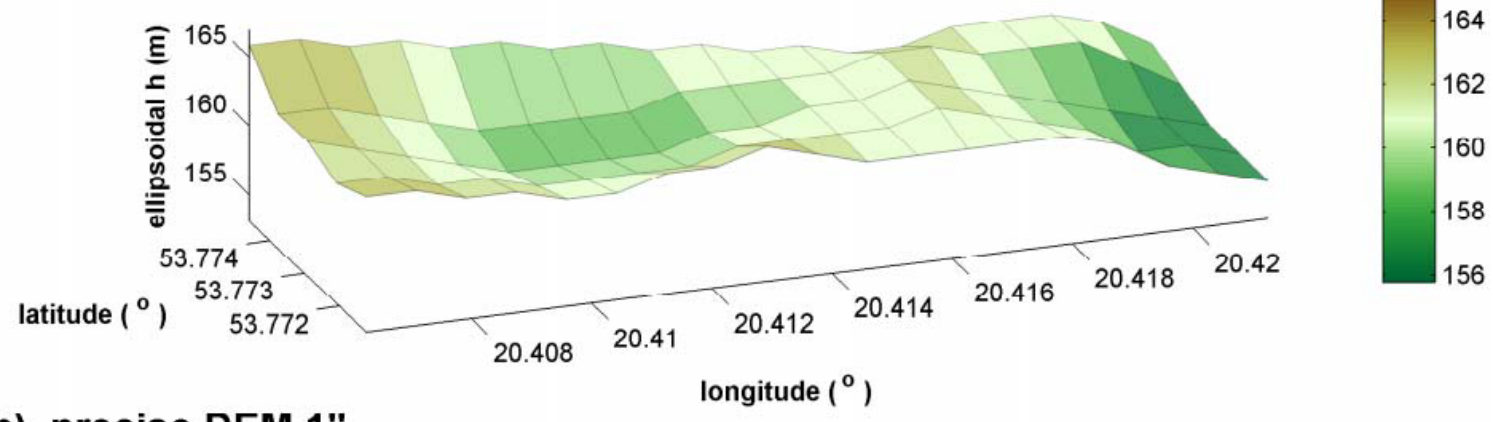

b) precise DEM 1"

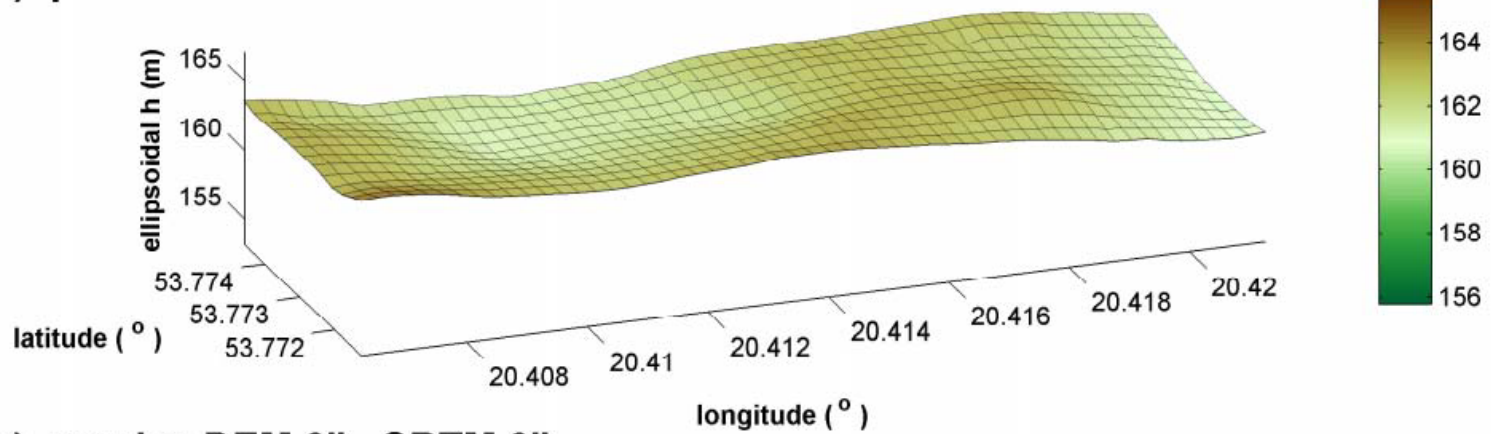

c) precise DEM 3" - SRTM 3"

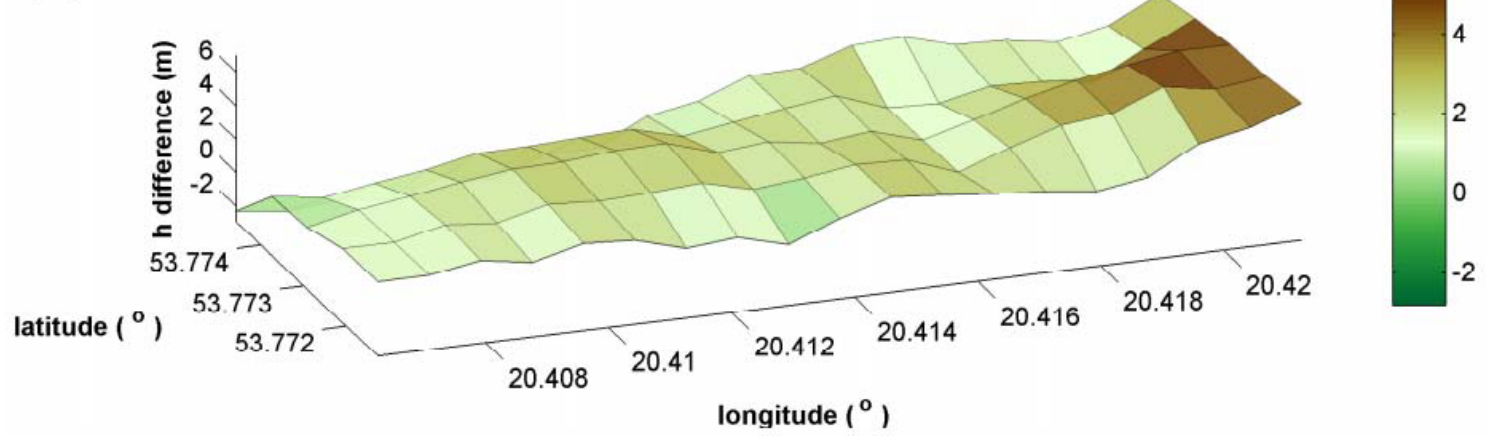

Fig. 6. DEM of Olsztyn airfield - ellipsoidal elevation.

a) SRTM 3" data; b) precise DEM 1" data; c) difference of precise DEM 3" and SRTM 3" in meters

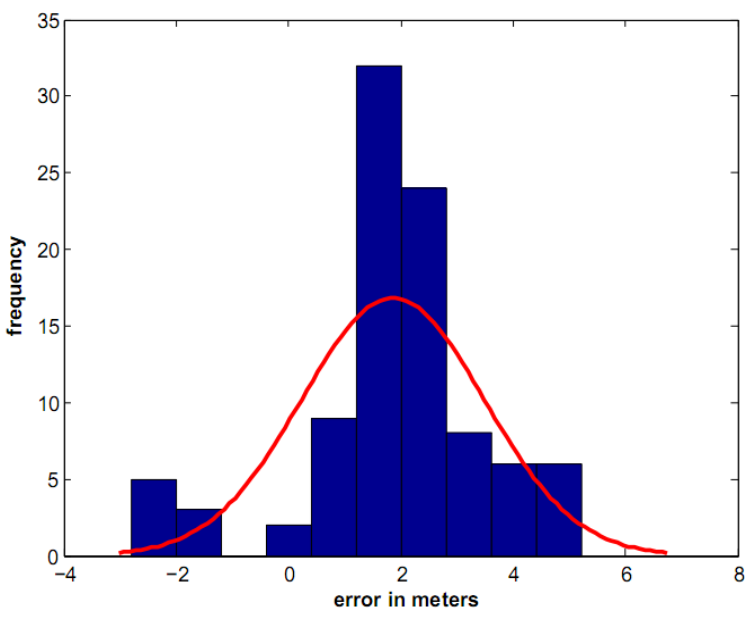

Fig. 7. Histogram representig errors in meters of SRTM 3" in comparison with precise DEM 
The final step of the generation of complete DEM of Olsztyn city was an integration of the highly accurate local DEM with SRTM model. The original SRTM data covering the area of Dajtki airfield was removed and replaced with precise local DEM - Fig. 8. The result is a complete DEM of Olsztyn with high accuracy model of the airfield. Model can be completed with air obstacles, which fulfils needs of a complete system. In this project the highest in Poland TV tower was also added to the model.

Such a model can be used in different applications supporting air navigation. It can be especially useful in application for an approach and landing phase of the flight, providing vital, real time information to the pilot concerning altitude above the terrain, aircraft position relative to the descent path, distance to the obstacles, etc. Precise and accurate position of the aircraft derived from GNSS/INS systems integrated with produced model can also generate real-time warnings.

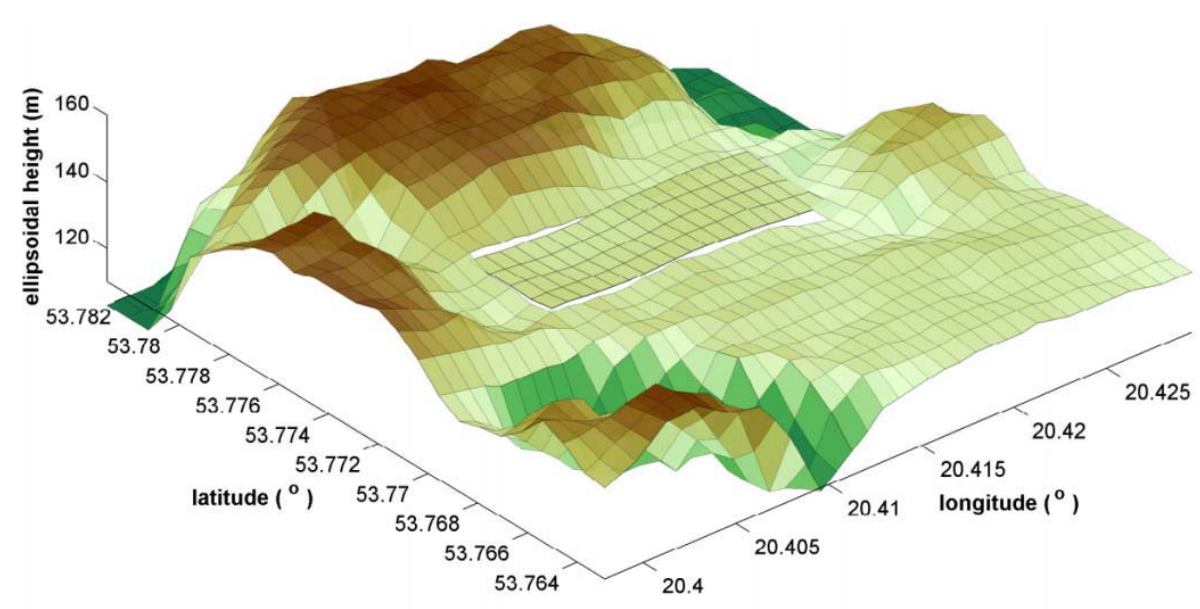

Fig. 8. Precise DEM of Dajtki airfield integrated with SRTM model

\section{VISUAL APPLICATION USING DEM FOR AIR NAVIGATION}

Test flight was made on August 31, 2012. Position of the aircraft was determined with centimetre accuracy for each second of the flight using RTK post-processing mode (Grzegorzewski et al., 2008). Using data of a sample flight prototype software was developed which integrates and combines the position of the aircraft with the terrain model and air navigation obstacles. The application provides user with up to date relevant flight parameters such as current altitude above the terrain, distance to the obstacles and the aircraft position relative to the glide path. The application was written using Mathlab v. R2011b Software.

For calculations of small ellipsoidal distances, the spherical approximation was used instead. The formula for spherical distance is following.

$$
\cos \psi_{P Q}=\cos \theta_{P} \cos \theta_{Q}+\sin \theta_{P} \sin \theta_{Q} \cdot \cos \left(\lambda_{Q}-\lambda_{P}\right)
$$

where: $\theta_{\mathrm{P}}=90-\varphi_{\mathrm{P}}$ is so-called polar distance.

Small distances were calculated in meters in an approximate way, i.e.

$$
\begin{aligned}
& \delta \varphi(m)=\left(\varphi_{Q}-\varphi_{P}\right) \cdot \frac{2 \pi}{360} \cdot R \\
& \delta \lambda(m)=\left(\lambda_{Q}-\lambda_{P}\right) \cdot \frac{2 \pi}{360} \cdot r
\end{aligned}
$$


where: $\mathrm{R}$ is the sphere radius, and $\mathrm{r}$ is the radius of parallel i.e. $\mathrm{r}=\mathrm{R} \cos \varphi$.

The vertical geometry of the glide path is computed simply using relation:

$$
\mathrm{h}_{\mathrm{g}}=\mathrm{h}_{\mathrm{R}}+\psi_{\mathrm{Rg}} \cdot \tan \alpha
$$

where $h_{g}$ is the height of glide path, $h_{R}$ is height of the runway, $\psi_{\text {Rg }}$ is the spherical distance and $\alpha$ is the slope of the glide path.

The horizontal geometry of the glide path is computed using planar distance from the straight line (Bronsztejn et al. 2004). The normal equation of the straight line reads:

$$
\mathrm{Ax}+\mathrm{By}+\mathrm{C}=0
$$

Replacing planar coordinates with the increments in latitude and longitude (eq. 3-4), the coefficients of the glide path may be computed in a following way:

$$
\begin{gathered}
\mathrm{A}=\lambda_{\mathrm{W}}-\lambda_{\mathrm{E}} \\
\mathrm{B}=\varphi_{\mathrm{W}}-\varphi_{\mathrm{E}} \\
\mathrm{C}=\varphi_{\mathrm{W}} \cdot \lambda_{\mathrm{E}}-\varphi_{\mathrm{E}} \cdot \lambda_{\mathrm{W}}
\end{gathered}
$$

The subscripts $\mathrm{W}$ and $\mathrm{E}$ denote the starting and the ending point of the runway. After computing of the coefficients the horizontal distance may be derived as follows:

$$
\mathrm{d}=\frac{\mathrm{A} \varphi+\mathrm{B} \lambda+\mathrm{C}}{\sqrt{\mathrm{A}^{2}+\mathrm{B}^{2}}}
$$

Designed application has a graphical interface which presents horizontal and vertical distances to air obstacles (within defined vicinity) and within specified distance to runway it also informs pilot about current position with respect to the glide path, elevation to SRTM/precise DEM, ellipsoidal elevation and distance to runway - Fig. 9.
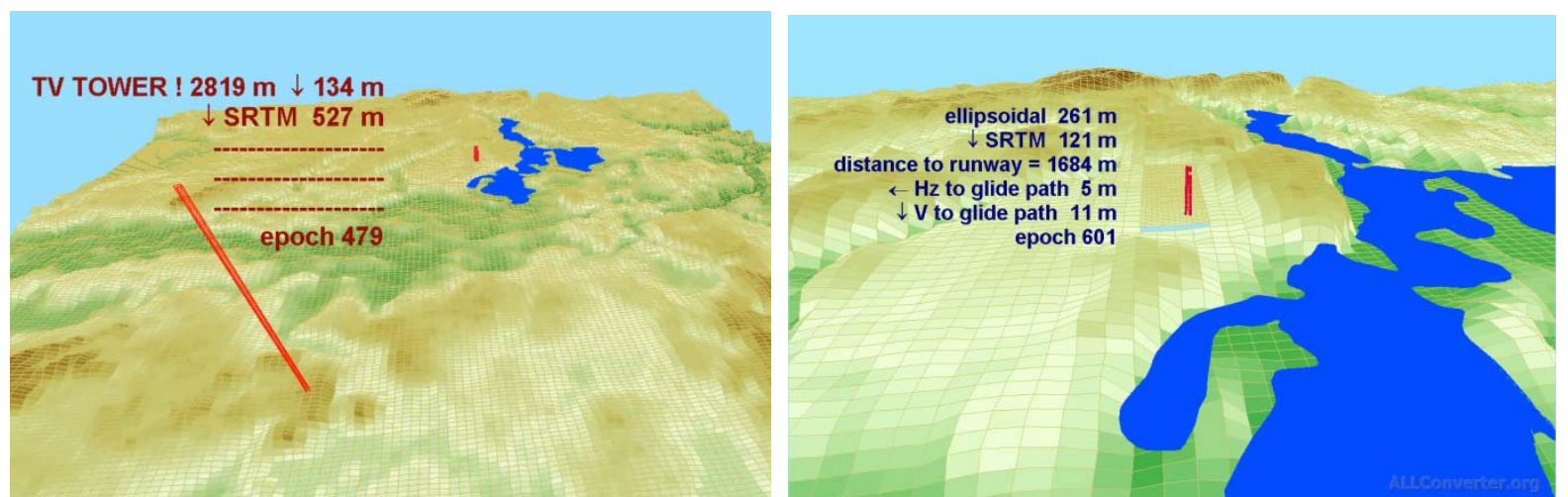

Fig. 9. Proximity warning concerning air obstacle (left) and information on vertical and horizontal distance to glide path, elevation to SRTM and distance to runway (right)

The data filelds in the application can be freely modified for the present needs and for convenience of pilot. Currently the application works in post-processing mode and presented test data were calculated in RTK post-processing mode but it is planned to create a version working in real time. Different modes of real time positioning including: autonomous, DGPS, 
network DGPS (Bakula, 2010), EGNOS/WAAS (Grzegorzewski et al., 2012) and RTK will be investigated. Integration of GNSS solution with INS output is essential for the project as well as creation of prediction model of air navigation.

The application allows for many different analyses of the flight parameters. Graphs concerning detailed analyses of required parameters can be prepared quickly and effectively. Figure 10 presents SRTM height along trajectory of the plane during landing phase and vertical distance to glide path.

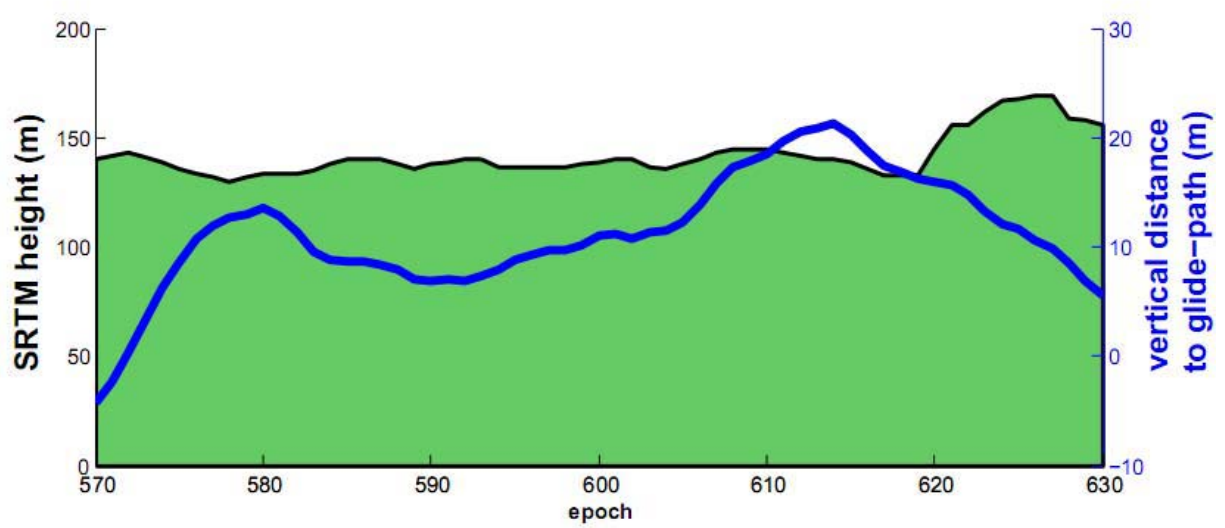

Fig. 10. SRTM height along descent trajectory and vertical distance to the glide path (final phase of the approach)

Histograms given in Figure 11 represent horizontal and vertical distance in metres to glide path during approach and landing of a plane. These graphs can be used for the study of the impact of different factors on trajectory along glide path. For example the influence of the wind can be investigated as well as skills of the pilot can be easily determined.

a) $\mathrm{Hz}$ distance to glide-path

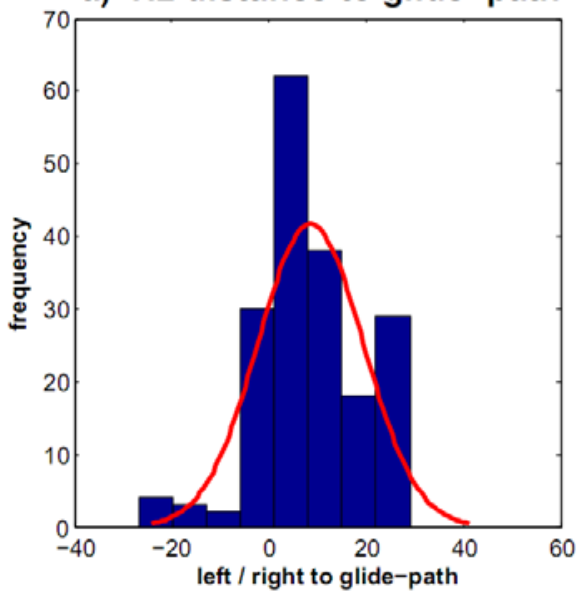

b) V distance to glide-path

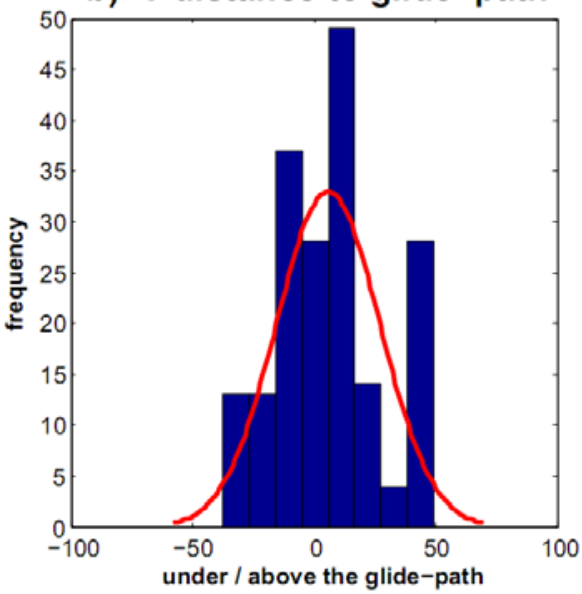

Fig. 11. Histograms representing horizontal and vertical distance in metres to glide path during approach and landing

\section{CONCLUSIONS}

The experiment shows that there are few meters errors in SRTM, therefore its integration with precise DEM is a significant refinement for modelling aircraft position with respect to elevation data. Moreover, for limited area the slope of the differences (Fig. 6c) may indicate that some systematic effects exist also in total SRTM error. They may come from e.g. modelling of heterogeneous data composed of terrain and the forest canopy. The separation 
between the glide path and SRTM/precise DEM may be worth further investigation and analyses but more test data is needed for this purpose. It is also interesting how the pilot's work may be analyzed using this kind of tools, especially during the approach phase. Similar analyses may support e.g. stability of different flight parameters when approaching the terrain (Fig. 11).

The future work will be mainly focused on study of different geometrical parameters useful in various flight phases and analyses on GNSS/INS positioning. The study on prediction algorithm and its integration with presented application for safe air navigation is also a goal of these works.

The project is still under development, however several tasks have been already completed including creation of precise DEM of test airfield, integration of SRTM and precise DEM with detailed analyses and creation of prototype application integrating positioning with DEM. Application is especially dedicated to small aircraft and airfields. Precise database of small grass or concrete airfield can be prepared quickly and effectively. Very important outcome of performed work is possibility of quick modifications of the application according to individual needs and airfield location. There is also a possibility of the implementation of real-time mode for safe air navigation.

Acknowledgments. This work was supported by the grant funded by National Science Centre of Republic of Poland (No N N526 245640).

\section{REFERENCES}

ALAR Approach and Landing Accident Reduction Tool Kit (2001), Flight Safety Foudation, v. 3.0 .

Bakuła M. (2010), Network Code DGPS Positioning and Reliable Estimation of Position Accuracy, Survey Review, 42, 315, pp. 82-91.

Braun A., Fotopoulos G., (2007), Assessment of SRTM, ICESat, and survey control monument elevations in Canada, Photogrammetric engineering and remote sensing 73 (12), pp. 1333-1342.

Bronsztejn I.N, Siemiendiajew K.A., (1996), Mathematics. The encyclopedic handbook, Warsaw, Polish Scientific Publishers PWN

Ciećko A., Oszczak B., Oszczak S., (2006), Efficient and Cost-Effective Generation of Precise Digital Terrain Model (DTM) with the Use of GPS and GSM/GPRS Technology, ION NTM 2006, Monterey, California, USA, 18-20 January 2006, pp. 490-496

Ciećko A., Oszczak B., Oszczak S., (2006), Drive-by DTM - GPS and GSM Power CostEffective Terrain Modeling - GPS Word, Vol. 17, No. 4, April 2006, pp. 44-49

Erol B., (2012), Spectral evaluation of Earth geopotential models and an experiment on its regional improvement for geoid modelling, Journal of Earth System Science, June 2012, Volume 121, Issue 3, pp 823-835

Grzegorzewski M., Ciećko A., Oszczak S., Popielarczyk D., (2008), Autonomous and EGNOS Positioning Accuracy Determination of Cessna Aircraft on the Edge of EGNOS Coverage - ION NTM, San Diego, CA, USA, January 28-30 2008, pp. 407-410

Grzegorzewski M., Świątek A., Oszczak S., Ciećko A., Ćwiklak J., (2012) - Study of EGNOS Safety-of-Life service during the period of solar maximum activity, Artificial Satellites, Vol. 47, No. 4 - 2012, pp. 137-145

Hofmann-Wellenhof B., Moritz H., (2005), Physical Geodesy, Springer, New York. 
Karwel A. K., Ewiak I., (2006), Estimation of the accuracy of the SRTM terrain model in Poland, Archiwum Fotogrametrii, Kartografii i Teledetekcji, Vol. 16, pp. 289-296

Popielarczyk, D. (2011), Application of global navigation satellite system and hydroacoustic techniques to safety of inland water navigation, Archives of Transport 23 (2), pp. 191-207

Rabus B., Eineder M., Roth A., Bamler R., (2003), The shuttle radar topography mission-a new class of digital elevation models acquired by spaceborne radar, ISPRS Journal of Photogrammetry and Remote Sensing 57.4, pp. 241-262.

Reuter H.I, Nelson A., Jarvis A., (2007), An evaluation of void filling interpolation methods for SRTM data, International Journal of Geographic Information Science, Volume 21 Issue 9, January 2007, pp. 983-1008

Sun G., Ranson K.J., Kharuk V.I., Kovacs K., (2003), Validation of surface height from Shuttle Radar Topography Mission using shuttle laser altimeter, Remote Sensing Environment Vol. 88, pp. 401-411.

Trojanowicz M., (2009), Ocena dokładności globalnych modeli geopotencjału EGM96 $i$ EGM08 na obszarze Dolnego Ślaska, Acta Sci. Pol., Geodesia et Descriptio Terrarum 8(1) 2009, pp. 19-30.

Received: 2013-01-02,

Reviewed: 2013-06-06, by J. Ćwiklak,

Accepted: 2013-11-19. 